\title{
Currency hedging strategy using barrier options in the Colombian market
}

\author{
Mariana Arango-Franco ${ }^{1}$, Miguel Jiménez-Gómez ${ }^{2}$, Natalia Acevedo-Prins ${ }^{3}$ \\ ${ }^{1,2}$ Facultad de Minas, Universidad Nacional de Colombia, Colombia \\ ${ }^{2,3}$ Facultad de Ciencias Económicas y Administrativas, Instituto Tecnológico Metropolitano-ITM, Colombia
}

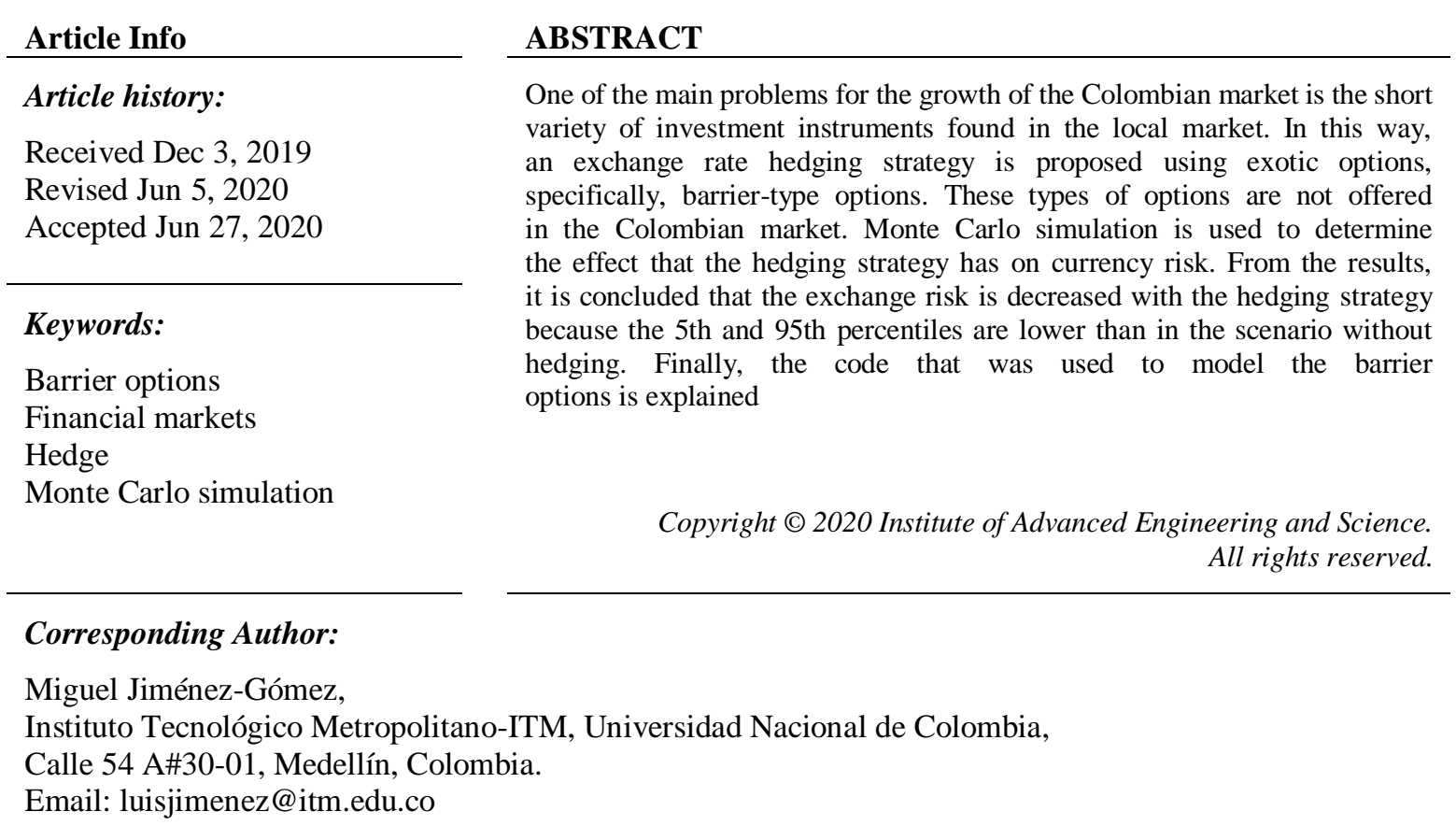

\section{INTRODUCTION}

Financial markets bring multiple advantages to the economy of the countries that have them. These advantages can be summarized in a greater diversification of risk, major incentives for foreign investment, mobilization of savings and their allocation in productive investments, stable financing for the public and private sectors, and cheaper credits at global level. All these advantages are essential for the growth and stability of a country [1,2]. For that reason, it is fundamental for emerging economies to develop solid, broad and deep financial markets.

On the other hand, the globalization of the economy and the insertion in the international markets trigger the migration of the countries to the use of a floating exchange rate regime, which means that the exchange rate becomes determined by the forces of the market. In these conditions, and with an extremely changing international economy, the behavior of the peso/dollar exchange rate went from a typically bullish trend (permanent devaluation of the peso) to a high volatility (erratic trend with unpredictable movements of devaluation and revaluation of the peso). This exchange rate phenomenon means that the Colombian currency will be more exposed to variations in the international market, so it will be associated to greater volatility. As a consequence of this, Colombian companies with participations in the international markets must seek different alternatives that allow them to obtain hedge to protect themselves from exposure to currency risk [3].

Due to the importance that investors or companies have been given to the risk administration, the derivatives market has become an essential part of the financial markets in the world.The financial derivatives are instruments of risk hedging designed for the actors at financial markets that do not seek to obtain profits from speculation, but from real productive activity [4, 5]. Because of the above, and pursuing the objective of developing, expanding, modernizing, deepening, and innovating in the stock markets, in 2008, Colombia became the third country in Latin America to create a platform for the market of standardized 
derivatives through the Bolsa de Valores de Colombia $[3,6]$. Through this platform, some projects have been developed in order to incorporate futures and options as new investment and financing alternatives which represent a lower risk for investors [7].

Based on the foregoing and on the studies conducted by Jiménez and Zabala, it can be clearly concluded that one of the main reasons that motivate companies to use derivatives is the losses hedging. These losses may be generated by the exchange of foreign currency in the future, so it can affect its balance sheet accounts. Some examples in which derivatives have been used to mitigate currency risk are in the papers presented by Shou-ting Chen, Xun-di Diao and Ai-lin Zhu, by Susana Álvarez, Eva Alfaro and Matilde Fernández, and by Jhon Alexis Days, Gloria Inés Macías and Edgar Luna Gonzále. All of the paper above expose the benefits associated with currency hedging, and they highlight the extra benefits that obtains the companies that have large exposures to currency risk [8-10].

In this manner, the purpose of this paper is to make a currency hedge using barrier options with local underlying assets. It is aiming to demonstrate the flexibility that can be achieved in the local market through innovations in financial instruments, and to contribute to a faster and sustained growth of advanced economies and emerging markets. To achieve this, the first topic that is going to be studied are the types of traders, especially the hedgers, because under this role will work this article. Then the financial options will be reviewed, and a deeper explanation about exotic options will be given. Exotic options take on special importance due to their ability to adapt to the needs of the different investors, which makes the derivatives market much more attractive. Subsequently, the operation of exotic options will be analyzed, focusing the analysis on barrier options. After knowing about this financial instrument, the methodology that is going to be implemented for the currency hedging will be described and the results obtained will be discussed.

\subsection{Currency hedging}

Currency risk is defined as the probability that the actual domestic purchasing power of home or foreign currency on a given future date will differ from its originally anticipated value. In other words, currency risk refers to the value variability of assets, liabilities, and transactions for a company because of unanticipated changes in the exchange rate. It is important to note that currency risk is different from exposure because exposure should be defined in terms of what one has at risk [11, 12].

There are tree types of risk exposure: Economic exposure (or operational exposure): it is the impact of the variability of the exchange rates on the company's value. This means the impact that alteration on exchange rates generate on future cash flows, for both foreign currency and for local currency. Exposure in the transaction (or contractual exposure): it is the impact that may have the not predicted alterations in the exchange rate on the completion of transactions which involves conversion of currencies. Exposure in the conversion (or accounting exposure): it is the impact that the exchange rate may have on the consolidated financial statements of a company $[12,13]$. Exchange risk exists regardless of whether people invest in the country of origin or abroad, so it always exists when there is transaction that involves currency exchange. As it was already mentioned, one of the main functions of derivative instruments is to provide a hedging mechanism against an existing risk. That risk is related with fluctuations in the price of the underlying asset that may cause losses to the participant agents.

A study published by Allayani and Ofek about companies that make up the S\&P stock index found that derivatives market is being used from those companies to cover the currency exposure held by them. This risk was generated by income and debts denominated in foreign currency [14]. Like most of the companies described above, in this paper the hedge will be used with the objective of avoiding the exchange risk associated with the shares in the Bolsa de Valores de Colombia.

\subsection{Financial options}

An option is a contract that gives the holder or the buyer of the option the right to buy or sell a stock or a value on a predetermined date and at a pre-established price, but it is not an obligation. In case the buyer exercises this right, the option grants the seller or subscriber of the option the obligation of sell or buy the stock or value [3]. Based on the foregoing, it can be concluded that the rights and obligations of the buyer and the seller in the options contracts are asymmetric. In other words, the buyer has a right that can be exercised or not, and it strongly depends on the pertinence or convenience of the transaction on the expiration date of the contract. On the other hand, the seller only has obligations because if the buyer decides to exercise the right, the seller is obligated to sell or buy the underlying asset [3].

Some important elements of the option contracts are the seller, the buyer, the expiration date, the strike price, the option price, and the underlying asset of the option. Those elements are shortly described below: Seller: person who agrees to buy or sell an underlying asset. Buyer: person who obtains the right to buy or sell an underlying asset. Expiration date: it is and pre-established date on which the option contract expires. It is 
also known as the maturity date. Strike price: it is the price agreed upon in the option contract, and it is also known as exercise price. This price is commonly known as K. Option price: it is the prepayment that must be made by the agent participating in the contract. Underlying asset: it is the asset or good that is stipulated in the contract. The negotiation is based on the price of this asset $[15,16]$. In general, the use of options brings multiple advantages. The greatest advantage is that they reduce the systematic risk that traders have in the market, and they are an appropriate financial instrument to hedge. In addition, the use of options brings with it a reduction in transaction costs and the opportunity costs of having cash, facilitates the alteration of the level of risk involved in investments, and allows to easily modify the return profiles, so it contributes towards a positive return on investment [17]. It should be noted that the performance obtained after the use of options and the risk associated with them depends completely on the strategy employed by the trader [18]. Regarding to options, there are two important aspects that must be taken into count. The first one is the classification of the options, and the second one is the position that the investor takes in the option contract. Sections 2.1 and 2.2 will go deeper into these aspects.

\subsection{Exotic options}

Exotic option or nonstandard options are all the options nontraditional. Traditional options have a fixed strike price and their prices or implied volatilities are quoted by exchanges or by inter-dealer brokers on a regular basis, namely they have well-defined properties. In contrast, exotic options do not have standard well-defined properties [19]. These exotic products are developed for several reasons. One of those reason is the reducing of the cost of traditional options; sometimes they meet a genuine hedging need in the market; additionally, there are tax, accounting, legal, or regulatory reasons why corporate treasurers, fund managers, and financial institutions find exotic products attractive; occasionally an exotic product is designed by a derivatives dealer to appear more attractive than it is to an unwary corporate treasurer or fund manager; and so on $[9,20]$. Based on the foregoing, exotic options aim to overcome the limits that standard options have and to offer more flexibility in the market. To construct exotic options, plain vanilla options are used as basis, and later there are some modifications made on certain conditions. The options that are going to be used in this paper are the barrier options, so they are explained below.

\subsection{Barrier options}

Barrier options or conditional options are options where the payoff depends on whether the underlying asset's price reaches a certain level during a certain period. Its probability of exercise depends on the underlying asset to reach a certain level, known as a barrier [19]. These type of exotic options are considered as an extension of the plain vanilla options or simple options because the option pricing of the plain vanilla options depends on the strike price, whereas the option pricing of the barrier options depends on the strike price and the barrier [21].

In general terms, barrier options are canceled or activated depending on the values taken by the underlying asset. The main advantage of this type of options is its price because they are less expensive than the corresponding regular options. This saving in cost is due to three factors: the proximity of the barrier, the time frame of the option and its volatility. These barrier options can be classified as either knock-out options or knock-in options. Knock-in options: a knock-in option comes into existence only when the underlying asset price reaches a barrier. When this happens, the barrier option becomes in a simple call option or a simple put option. There are two types of knock-in options: up-and-in options and down-and-in options.

An up-and-in option is a regular option that comes into existence only if the barrier is reached at some point of time before the expiration date; whereas an down-and-in options is a regular option that comes into existence only if the asset price do not reach the barrier level during the validity time of the option. Knock-out options: a knock-out option ceases to exist when the underlying asset price reaches a certain barrier, so this type of option can be only exercised if the underlying asset do no reach the barrier [15, 22, 23]. Same to the knock-in options, there are two types of knock-out options: up-and-out options and down-and-out option.

An up-and-out option is a regular option that ceases to exist if the asset price reaches a barrier level; whereas a down-and-out option is a regular option that comes into existence if the asset price reaches a certain barrier level. Regarding to barrier options in general, both knock-in options and knock-out options, it is important to note that their option pricing is closely related to the plain vanilla option pricing. For instance, the price of a down-and-out call plus the price of a down-and-in call must be equal to the price of a regular European option (when exercise prices, expiration dates and barrier levels are equal). In the same way, the price of a down-and-out put plus the price of a down-and-in put must be equal to the price of a regular European option [15]. 


\section{RESEARCH METHOD}

Pursuing the objectives of offering new hedging alternatives to Colombian companies and diversifying the type of investment instruments offered in the Bolsa de Valores de Colombia, a currency hedging model is proposed using up-and-in options with currency as the underlying asset. This type of exotic option will be used because the proposed model will review the specific case of a buyer. The proposed methodology is from quantitative nature, since it handles updated information from the local derivatives market to propose the model described above and for its subsequent financial analysis.

The information that is going to be used for modeling will be taken from the databases of the Bolsa de Valores de Colombia. The prices of the underlying asset, which in this paper will be the exchange rate of the Colombian peso (hereinafter TRM), will be taken from April 24, 2015 to November 23, 2019. From the information taken from the databases, the information presented for Saturdays, Sundays and holidays will be eliminated because on those days the TRM is not quoted, and this may generate errors in the estimation of the options prices. Based on the above, T0 is defined as the date on which the simulations were performed and the last date present in the history of the TRM, that is November 23, 2019. The tools that will be used for the development of the model will be the Geometric Brownian Motion and the Monte Carlo simulation. The use of these tools will allow modeling of the future behavior of the TRM's prices, calculating of the option price, valuing of the compensation, and predicting the expected price of the hedging.

\subsection{Geometric brownian motion}

The Geometric Brownian Motion (GBM) is the continuous time stochastic process that is mainly used for future pricing simulation of a financial asset based on the databases of it. For the GBM to be effective, the following properties must be complied [24]:

- The company is a going concern, and its stock prices are continuous in time and value.

- Stocks follow a Markov process, meaning only the current stock price is relevant for predicting future prices.

- The proportional return of a stock is log-normally distributed.

- The continuously compounded return for a stock is normally distributed.

It is important to note that each of these assumptions influences the GBM model and its inputs. The mathematical formulation for the GBM is shown in (1):

$$
S_{T}=S_{0} * e^{\left(\mu-\sigma^{2} / 2\right) \Delta t+\sigma \sqrt{\Delta t} \xi}
$$

Where ST is the future price of the financial asset; S0 is the last known price of the asset, which will be $\$ 2,757.96$ for the application case because it corresponds to the last data of the historical series of the TRM; $\mu$ and $\sigma$ represent the average of returns and volatility, respectively (both are constant); $\Delta t$ represents the period of time in which the prices will be presented, and for this case will be on a daily basis; finally, $\xi$ is a random number that follows a normal distribution with zero mean and standard deviation of 1 [25]. The returns and volatility of the asset are calculated as follows in (2) and (3):

$$
\begin{aligned}
& R \_i=L n \rrbracket\left[f_{0}:\left(S \_i / S \_(i-1)\right)\right. \\
& \sigma=\sqrt{ }\left(1 /(n-1) \sum(i=1)^{\wedge} n \text { 非 }\left(S \_i-\mu\right)^{\wedge} 2\right)
\end{aligned}
$$

Where $\mathrm{Si}$ is the price that the asset has at time $\mathrm{i}$; $\mathrm{Si}-1$ is the previous price $(\mathrm{i}=1, \ldots, \mathrm{n})$, and $\mathrm{n}$ is the total of the data. After making the calculations, it is obtained that the average of returns $(\mu)$ will be defined as $0.2375 \%$ continuous annual and $\sigma$ as $13.9166 \%$ continuous annual. For this specific case, certain modifications will be made to the model presented in the Equation 1 due to the type of underlying asset which this paper is going to work with. The modifications will be the change of $\mu$ for the risk-free rate (r) and the inclusion of the foreign risk-free rate (rf) [26]. The modified equation is presented in (4).

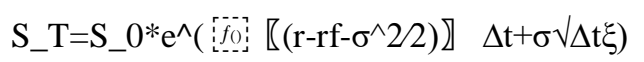

The domestic risk-free rate will be defined as the current IBR for six months because the validity time of the option for the hedging will be established as 180 days. This rate is $4.0076 \%$ continuous annual, and it was obtained from the Bolsa de Valores de Colombia. Regarding to the foreign risk-free rate, it was defined as the currently valid for the United States Treasury Bonds. Its value is $2.0195 \%$ continuous annually and it was taken from the US Department of the Treasury.

\subsection{Simulations code and programming}


R-Studio is going to be used for programming and executing the simulations. The first thing that must be defined within the code are the constants that were already mentioned (S0, $\mu, \sigma, r$, rf). Afterward, it must be defined the period of validity that the option will have. Also, as this paper is dealing with barrier options, it must define what the barrier will be. Having this information within the code, the next step is to include the Geometric Brownian Motion to model the future behavior of the TRM prices and calculate the prices obtained with the hedging. The code used for modeling the future prices of the TRM is shown in Figure 1 and for modeling the option prices is presented in Figure 2.

$s t[i, j]>-s^{*} \exp \left(\left(m u-v_{0} 1 \wedge 2 / 2\right)=j+\operatorname{vol}=\operatorname{sqrt}(j)=\operatorname{epsilon)}\right.$

Figure 1. Code used for modeling the future prices of the TRM

st_option $[1, j]>-s^{*} \exp \left((r-r f-v 01 \wedge 2 / 2)^{*} j+\operatorname{vol}=\operatorname{sqrt}(j) * \operatorname{epsi10n}\right)$

Figure 2. Code used for modeling the option prices

After that, a conditional must be introduced because of the barrier option usage. In fact, the conditional is necessary because the possibility of exercise the option depends on the price of the underlying asset. If the underlying asset reaches the barrier, then the option will be executed, else the option will disappear. The conditional is shown in Figure 3.

if (st_option $[i, j]>$ parrier) [

Figure 3. Code used for conditional

If the price of the asset is greater than the barrier, the option will be activated. Subsequently, the compensations and the expected option price are calculated. For this case, the programming of the compensation, the option price, and the TRM price with hedging are shown in Figure 4, 5 and 6 respectively. Otherwise, if the price of the asset is lower than the barrier, the option disappears and there is no compensation. In this last case, the expected option price becomes in the predicted price for the TRM. For his case, the programming of the compensation, option price, and the TRM price with hedging are shown in Figure 7, 8 and 9 respectively.

$$
\text { payoff_cal1 }[v]>-\max (s t[v, m]-k, 0)=\exp \left(-(r-r f)^{*} m\right)
$$

Figure 4. Code used for calculating the compensation when the barrier is reached

payoff_cal1_option $[v]>-\max \left(s t \_o p t i o n[v, m]-k, 0\right)=\exp (-(r-r f)=m)$

Figure 5. Code used for calculating the option price when the barrier is reached hedge_price_cal1 $[\mathrm{v}]>-(-\mathrm{st}[\mathrm{v}, \mathrm{m}]+$ payoff_ca11 $[\mathrm{v}])$

Figure 6. Code used for calculating the TRM price with hedging when the barrier is reached

$$
\text { payoff_ca11 }[\mathrm{V}]>-0
$$

Figure 7. Code used for calculating the compensation when the barrier is not reached 
payoff_ca11_option [v]>-0

Figure 8. Code used for calculating the option price when the barrier is not reached

hedge_price_cal1 $[\mathrm{v}]>-s t[\mathrm{v}, \mathrm{m}]$

Figure 9. Code used for calculating the TRM price with hedging when the barrier is not reached

Finally, once the previous programming is already done, it is only necessary to calculate the option price and the TRM price with hedging. This code is shown in Figure 10, 11 and 12.

$$
\text { ca11>-mean (payoff_ca11_option) }
$$

Figure 10. Code used for calculating the option price

$$
\text { hedge_price_ca11_cost }[\mathrm{a}]>- \text { hedge_price_ca } 11[\mathrm{a}]+\mathrm{ca} 11
$$

Figure 11. Code used for calculating the TRM price with hedging

$$
\text { mean_hedge_price_cal1_cost }>- \text { mean (hedge_price_ca11_cost) }
$$

Figure 12. Code used for calculating the average TRM price with hedging

\section{RESULTS AND ANALYSIS}

In figure 13 , the trend of the daily prices without and with hedging is presented. In addition, the percentiles of $97.5 \%$ and $2.5 \%$ are shown:
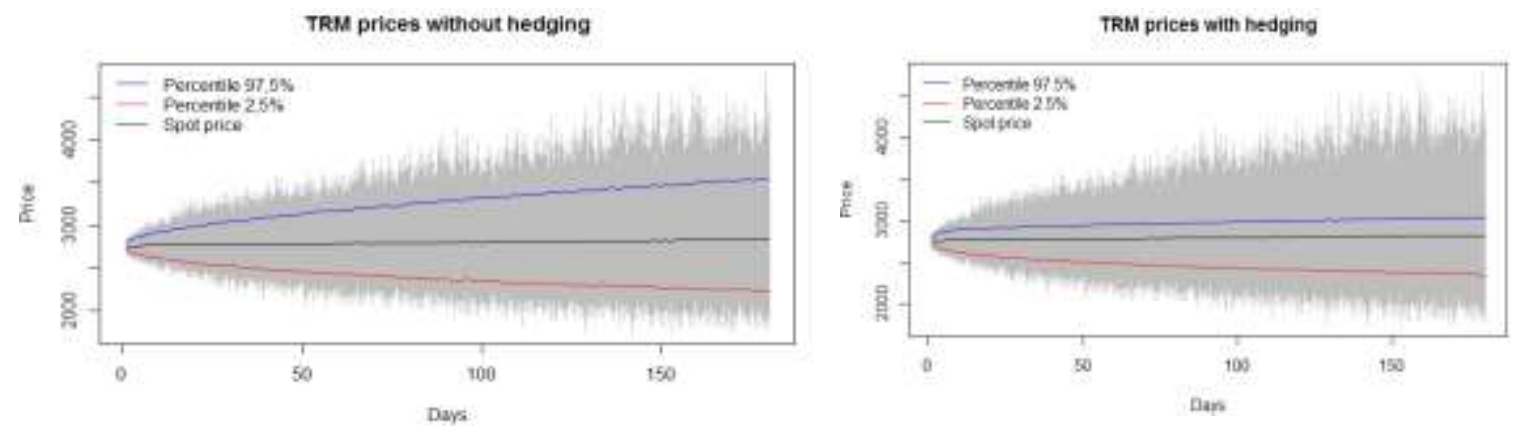

Figure 13. Trend of the daily prices without hedging

According to the results obtained, it is evident that the average price without hedging has a slightly increasing behavior. This corresponds to what is proposed in the model because the database of the historical price of the TRM suggests that the spot prices grow at a rate of $0.2375 \%$. The difference between the percentiles and the average price was much lower on the first days than the difference in the last days. Finally, it is important to note that the difference between the $97.5 \%$ percentile and the average price is very similar to the difference between the $2.5 \%$ percentile and the average price. There is less volatility in the average prices with hedging compared to the dispersion that presents the average price without hedging. This leads to the conclusion that the risk decreases significantly when investors use hedging strategies. It is also important 
to note that the average price with coverage tends more towards the $97.5 \%$ percentile, which suggests that there is a greater inclination toward a pessimistic scenario for the investor.

\section{CONCLUSION}

In the present paper, initial generalizations about the financial and derivatives markets were explained. After that the types of traders within these markets and the currency risk were briefly defined. The hedging strategies were also presented as financial alternatives to mitigate the currency risk. Then, financial options and exotic options were exposed. One type of those last were deeper explained because them represents the main object of study. After this contextualization, the methodology used was exposed, which was selected because it offers greater flexibility to be used in all kinds of options.

Regarding the application of the methodology, satisfactory results were obtained. It was possible to demonstrate the benefits that currency hedges bring to buyers because through the modeling the currency risk which buyers are exposed to was reduced and lower TRM prices were obtained. It should be noted that these benefits are enhanced or increased depending on the level of exposure to currency risk that the buyer has and the duration of the hedging. The affirmation above is due to the direct relation that exist between risk and benefits: higher level of exposure becomes in greater benefits for the buyer, and it also works for the validity time of the option: longer hedging's duration becomes in greater benefits for the buyer.

The results obtained with this paper may be considered as significant contributions to the derivatives market diversification process from Colombia, since it proposes the use and inclusion of new and varied alternatives for investors. In addition, it offers a detailed analysis that shows the benefits that buyers can obtain when applying currency hedging strategies. For purposes of future researches, it would be interesting to implement this methodology or a variation of it for hedging strategies associated with sellers and for longer periods of time, so the benefits that may be obtained with hedging are much more noticeable.

\section{REFERENCES}

[1] S. Vanitha and K. Saravanakumar, "The usage of gold and the investment analysis based on gold rate in India," Int. J. Electr. Comput. Eng., vol. 9, no. 5, pp. 4296-4301, 2019.

[2] L. B. Preciado and V. Camacho Roger, "How to develop an investment portfolio considering the different alternatives that voluntary pension funds offer in Colombia: The case of Skandia," Estud. Gerenciales, vol. 25, no. 113, pp. 229-241, 2009.

[3] I. D. Ochoa and C. González, "Evaluación del mercado de opciones sobre tasas de cambio: Perspectivas para una mejor utilización," Rev. EIA, vol. 7, pp. 145-158, 2007.

[4] O. Hadzic and S. Bisanovic, "Risk assessment for ancillary services," Int. J. Electr. Comput. Eng., vol. 9, no. 3, pp. 1561-1568, 2019.

[5] N. R. Sari, W. F. Mahmudy, A. P. Wibawa, and E. Sonalitha, "Enabling external factors for inflation rate forecasting using fuzzy neural system,” Int. J. Electr. Comput. Eng., vol. 7, no. 5, pp. 2746-2756, 2017.

[6] C. Ochoa, C. Jaramillo, and L. Montoya, “Existen Ganancias Por La Cobertura De Riesgo Cambiario En Un Portafolio De Acciones Global, Desde La Perspectiva De Un Inversionista Colombiano?,” Estud. Gerenciales, vol. 27, no. 120, pp. 83-103, 2011.

[7] N. Cañas Arboleda, "Perspectivas del Mercado de Derivados en Colombia: Retraso derivado del desconocimiento," AD-MINISTER, vol. 9, pp. 156-166, 2006.

[8] S. Chen, X. Diao, and A. Zhu, "Valuation and Hedging Strategy of Currency Options under Regime-Switching JumpDiffusion Model," Acta Math. Appl. Sin. English Ser., vol. 33, no. 4, pp. 871-892, 2017.

[9] S. Álvarez Díez, E. Alfaro Cid, and M. Fernández Blanco, "Hedging foreign exchange rate risk: Multi-currency diversification,” Eur. J. Manag. Bus. Econ., vol. 25, no. 1, pp. 2-7, 2016.

[10] J. A. Díaz Contreras, G. I. Macías Villalba, and E. Luna González, "Estrategia de cobertura con productos derivados para el mercado energético colombiano,” Estud. Gerenciales, vol. 30, no. 130, pp. 55-64, 2014.

[11] M. Adler and B. Dumas, "Exposure to Currency Risk: Definition and Measurement," Financ. Manag., vol. 13, no. 2, pp. 41-50, 1984.

[12] M. M. Vivel Búa, "El riesgo cambiario y su cobertura financiera," Rev. Galega Econ., vol. 19, no. 2, pp. 1-5, 2010.

[13] A. M. Granda Ospina, L. M. Jiménez Gómez, and M. D. Rojas López, "Estrategia de cobertura cambiaria con opciones financieras para empresa importadora de partes y accesorios de vehículos en Colombia," Rev. Espac., vol. 38 , no. 54, pp. 2, 2017.

[14] N. Cardozo Alvarado, J. S. Rassa Robayo, and J. S. Rojas Moreno, "Caracterización del Mercado de Derivados Cambiarios en Colombia," Borradores Econ., vol. 9, pp. 7-79, 2015.

[15] J. C. Hull, “Options, futures and other derivatives,” Pearson Ed., 2012. 
[16] J. P. Uribe Salazar, "Derivados financieros como alternativa de cobertura frente al riesgo cambiario (Estudio de caso)," Pontificia Universidad Javeriana, Tesis, 2009.

[17] M. Natter, M. Rohleder, D. Schulte, and M. Wilkens, "The benefits of option use by mutual funds," J. Finan. Intermediation, vol. 26, pp. 142-168, 2016.

[18] G. Cici and L. F. Palacios, "On the use of options by mutual funds: Do they know what they are doing?," J. Bank. Financ., vol. 50, pp. 157-168, 2015.

[19] Hull J.C., "Options, futures, and other derivatives, 8th ed.," Boston: Pearson Education, 2011.

[20] M. C. Chuang, C. H. Wen, and S. K. Lin, "Valuation and empirical analysis of currency options," Int. Rev. Econ. Financ., vol. 66, pp. 71-91, 2020.

[21] E. Derman and I. Kani, "The Ins and Outs of Barrier Options: Part 1," in Derivatives Quartely, 1996, pp. 55-67.

[22] J. L. Crespo Espert, "Utilización práctica de las opciones exóticas: Opciones asiáticas y opciones barrera," Madrid, pp. 1001-1008, 2001.

[23] J. J. García Machado, M. P. Sancha Dionisio, C. Tejerio Rioja, and D. Toscano Pardo, “Opciones «exóticas»," Boletin Economico De Ice, no. 2673, pp. 1-8, 2000.

[24] C. Sengupta, "Financial Modeling Using Excel and VBA," Hoboken, New Jersey.: John Wiley \& Sons, 2004.

[25] C. N. Angstmann, B. I. Henry, and A. V. McGann, "Time-fractional geometric Brownian motion from continuous time random walks,” Phys. A Stat. Mech. its Appl., vol. 526, pp. 121002, 2019.

[26] J. C. Botero Ramírez and Á. M. Pérez Muñoz, "Opciones tipo barrera sobre la tasa de cambio Peso/Dólar," AD-MINISTER, vol. 11, pp. 64-79, 2007. 